YAJUAN DENG, Ph.D. ${ }^{1}$

E-mail: dengyajuan1223@163.com

MINGLI CHEN, M.Sc. ${ }^{1}$

(Corresponding author)

E-mail: 2018221235@chd.edu.cn

${ }^{1}$ College of Transportation Engineering

Chang'an University

Middle Section of South 2 Ring Rd., Xian,

710064, Shaanxi, China
Traffic Planning

Original Scientific Paper

Submitted: 19 June 2020

Accepted: 13 Nov. 2020

DOI: $10.7307 /$ ptt.v33i4.3637

\title{
IMPACTS OF REAL-TIME TRANSIT INFORMATION ON BUS PASSENGERS' TRAVEL CHOICES BASED ON TRAVEL BEHAVIOUR SURVEY
}

\begin{abstract}
Real-time transit information (RTI) service can provide travellers with information on public transport and guide them to arrange departure time and travel mode accordingly. This paper aims to analyse travellers' choices under RTI by exploring the relationship between the related variables of RTI and passengers' travel choice. Based on the stated preference (SP) survey data, the ordinal logistic regression model is established to analyse the changing probability of passengers' travel behaviour under RTI. The model calculation results show that travellers getting off work are more likely to change their travel choice under RTI. When data from the control and experimental groups are compared, the differences in route selection are significant. Specifically, passengers with RTI have a more complex route selection than those without, including their changes of travel mode, departure time, vehicles, and stop choices. The research findings can provide insights into the optimisation of intelligent transit information systems and the strategy of RTI. Also, the analysis of passengers' travel choice under $R T I$ in the transit network can help to improve network planning.
\end{abstract}

\section{KEYWORDS}

real-time transit information; travel strategy; traveller behaviour changes; travel time.

\section{INTRODUCTION}

Improving the efficiency of public transportation and user satisfaction has been widely studied for a long time [1]. Many cities are committed to make better use of the public transportation system and improve urban traffic by strengthening the intelligent service of public transportation. Among them, providing passengers with effective real-time transit information (RTI) has been a very popular practice in recent years [2-4]. The intelligent transit information studied includes: static information (e.g. bus routes, departure time-tables, and ticket price), RTI (e.g. estimated bus arrival time, estimated travel time, road congestion) and crowding in vehicles. Passengers who choose to travel by bus can arrange the travel route based on these information and their own travel needs [5].

In recent years, RTI is no longer limited to bus stops only. As platforms that are equipped with RTI are becoming more diverse, RTI is being displayed in different ways [6]. For example, displaying dynamic location of vehicles can help reduce the unreliability of public transport services [7]. In addition, in order to provide RTI to passengers in a more cost-effective manner, many software developers are beginning to adopt open data [8]. Therefore, research has been further expanded. For example, in order to assess the impacts of RTI that are obtained from electronic devices such as mobile phones, several stated preference (SP) surveys, and revelled preference (RP) surveys have been conducted [9]. These impacts are mostly related to passenger perception of time [10], passenger anxiety [11, 12], and their level of ride satisfaction.

First of all, some studies revealed that RTI has some positive effects, which helps improve the passengers' use of public transport system services [13, 14]. Among them, Zeng et al. [13] found that both qualitative and quantitative information can help passengers to be aware of their travel status. Passengers can arrange their departure time and travel route based on this information. They also demonstrated that the space-time distribution of passenger flow throughout the public transport network has changed significantly. Tang [15] developed a 
discrete choice model, which reflects the selection characteristics of passenger departure time under RTI. Hu et al. [16] showed that constructions along the way may increase travel time, and that such information changed traveller's route choices.

Second, the effects of different types of RTI are different. A survey conducted at the University of Maryland showed that the estimated bus arrival time can increase the passenger's personal sense of safety when they are travelling at night [17]. A network survey conducted in Seattle found that more than $32 \%$ of image information users have positively changed their perception of waiting time [18]. Similar findings indicated the passengers' increased demand for the diversity of the RTI service. The most critical requirement is the accuracy and timeliness of the information $[19,20]$. It can be seen that RTI plays an important role in changing the passenger route selection.

To sum up, travel choice under RTI will have significant impacts on the use of the entire public transport system [21]. Over the past few years, many researchers explored the influence of RTI on the passenger perceived time $[22,23]$ and assessed the benefits of providing information, such as reducing waiting time, relieving anxiety, and improving satisfaction [24]. Another vital influence on passengers is their change of travel choice and frequency during the entire trip, which can be quantitatively evaluated. For example, due to the accurate understanding of bus arrival time and total travel time, passengers can flexibly adjust their departure time, change travel modes, and choose different routes based on their time constraints. Judging by the empty seats in the bus and the arriving time interval between the two vehicles, they can choose the bus most preferred. Therefore, this paper focuses on passengers' travel choice changes under RTI. This research will help to evaluate the effectiveness of RTI and yield insights into the improvements of information contents. Also, the analysis of passengers' choices in the transit network can help to make the planning of this network more reasonable.

The rest of the paper is organised as follows. Following the general introduction and literature review, section 2 presents the SP survey-based data collection procedure and analyses the factors that impact passenger travel choices, and an ordinal logistic regression model is used to study the passenger travel choice under RTI service. In section 3, we present the modelling results and explore passenger behaviour and choices under RTI service. In section 4 , a brief discussion of major findings is given. Section 5 provides final conclusion and future research of this study.

\section{METHODOLOGY AND DATA COLLECTION}

\subsection{Travel choice changes}

When RTI service is available, travellers can make decisions based on these information and their previous travel experience. Most of the available studies showed that the most changeable attributes of passengers under RTI included their travel mode, departure time, route, and stop choices, which were the four most significant factors of travel decision-making [6, 11, 18, 25].

Change travel mode. The emergence of the RTI service and other intelligent transportation technologies allows passengers to have more confidence in the reliability and stability of public transport when faced with multiple travel modes. As for RTI with low repetition rate and high flexibility, it is easier for passengers to adjust their choices [5].

Adjust the departure time. In the previous car travel survey, departure time and route selection are often considered as a whole. However, when the RTI service is available, the passenger trip chain is considered adjustable during any point from the origin to destination [13]. In the case where the road network and path selection are complicated, passengers can first and foremost flexibly adjust the departure time according to their own needs. Generally speaking, passengers determine their departure time for the purpose of improving travel convenience and efficiency under the constraints of time, and research shows that a significant number of travellers are willing to change their departure time [26].

Bus route and vehicle choices. For a station with only one bus line, the vehicle load factor is generally not very high. At stops where RTI is available, passengers can know exactly where the bus is and then determine the waiting time. However, unlike single-line stops, passengers are more concerned about the total travel time [22]. A common situation is that the RTI shows that bus A will arrive first, but the full travel time of bus A takes longer than that of bus B. Under these circumstances, not all passengers will choose the bus that arrives first. 
Bus stop choices. A bus stop is the location or carrier where passengers most often make decision changes [11]. This includes departure stations, transfer nodes, and getting-off stations. For example, passengers with more than one choice at the starting point may not necessarily choose the nearest station but will consider the entire information of a certain travel route, i.e., the related vehicle departure interval, transfer convenience, and comfort level. In this case, the choice of transfer node and getting-off station will also become more changeable due to the influence of the RTI service.

\subsection{Questionnaire}

This study launches an investigation into the different passenger choices by conducting a stated preference (SP) survey. Therefore, we can use this data to analyse the decision-making characteristics of passengers who receive the RTI service in different situations.

With reference to the research on the choice of car drivers' travel routes under the influence of variable message board, various factors that may impact drivers' choices are summarised and analysed synthetically [21, 24]. Similarly, the content of the survey can be determined as follows: personal attributes of passengers, travelling attributes, tendency to change the travel route, and attitude of passengers towards RTI.

In this study, a total of 700 questionnaires were distributed in 15 bus stops in Yanta District, Xi'an, Shaanxi Province, China. According to the principles of screening in this survey, 660 valid questionnaires were ultimately obtained, with an effective rate of $94.3 \%$. Specifically, under the service of RTI, whether passengers will change their travel choices depends on the factors they consider when making impromptu choices. Those factors include tolerable waiting time, frequency of use of RTI, and accuracy of information. A horizontal comparison of these factors shows that passengers are always more prone to change travel choices when they are on the way home than when they are commuting to work. On the other hand, passengers who are willing to change their route choices are most concerned about whether the bus will make a detour during the trip, the level of comfort, waiting time, and whether the tickets fare will change as the commuting situation shifts. Figure 1 takes the tolerable waiting time as an example. The impact analysis of other factors is the same.

Figure 1 shows the relationship between the changes in travel choices and the tolerable waiting time. Whether the passengers are on the way from home to work or getting off work, the number of passengers who certainly change their routes selection becomes higher as the waiting time within the tolerable range becomes shorter. There is a negative correlation between tolerable waiting time and changes in travel choices. That means the longer the tolerable waiting time is, the less likely it is to change the original riding plan. These findings are consistent with the travel choice assumptions identified previously in this paper.

\subsection{Ordinal logistic regression}

According to the number of the dependent variable, the ordinal logistic regression model can be divided into binary choice models and multiple choice models. When the dependent variable is a multi-level categorical variable and the levels have an ordinal relationship, the ordinal logistic regression model is a

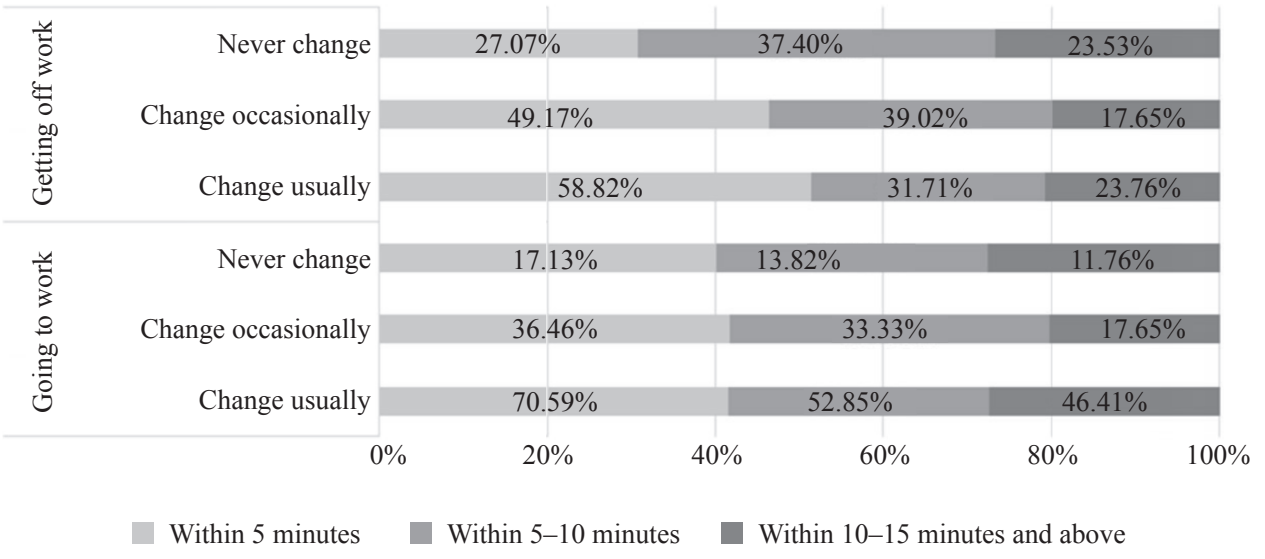

Figure 1-Tolerable waiting time and changes in travel choices 
natural choice. In our research we used the ordinal discrete choice model because the dependent variables included change path often, change path occasionally, and never change path. Furthermore, ordinal logistic regression is easier to understand than other ordinal discrete choice models. Therefore, the ordinal logistic regression model is used to study passengers' travel choices under the RTI service.

\section{Variable selection}

Model variables are based on the factor analysis approach. Independent variables consist of personal attributes, travelling attributes, tendency to change the travel route, and passenger attitude towards RTI. Correlation between those independent variables and travel choice requires further confirmation by calculating the significance level. The reference coefficient of the significance level is 0.1 . If the value is less than 0.1 , the correlation between the variables is significant. Results of the significance analysis are shown in Table 1.

Table 1 shows that the variables which are significantly correlated with travel choices include age, trip frequency, tolerable waiting time, travel considerations when changing travel paths, the presentation of RTI, the frequency of use of RTI, and the accuracy of information. Next, the numerical transformation and definitions of independent variables are shown in Table 2.

\section{Parameter estimation and model test}

This paper explores the impact and effectiveness of RTI on passengers' travel choices. The predicted passenger travel choices are as follows: changing travel choices usually, changing travel choices occasionally, and never changing travel choices. Judging by the characteristics of data and variables, we choose the ordinal logistic regression. The behavioural theory of this model is based on random utility theory, following the principle of utility maximisation. The utility function can be expressed as follows:

$U_{i}=V_{i}+\xi_{i}$

$V_{i}=\sum_{n=1}^{N} \theta_{n} X_{i n}$

where $U_{i}$ represents utility value of the $i$ th travel choice; $V_{i}$ represents fixed utility value of the $i$ th travel plan; $\xi_{i}$ represents random utility value of the $i$ th travel plan; $\theta_{n}$ represents the coefficient corresponding to the $n$th variable in travel plan $i ; X_{i n}$ represents the nth variable in travel plan $i$. Since there are three final passenger choice plans, the multivariate ordinal logistic regression model is used, which can be expressed as follows:

$$
P\left(y_{m}=i\right)=\frac{\exp \left(c_{m} \alpha_{i}\right)}{\sum_{k=1}^{K} \exp \left(c_{m} \alpha_{k}\right)}
$$

where $y_{m}$ represents the $m$ th bus passenger's decision on travel modes; $c_{m}$ represents the decision variable of the $m$ th bus passenger; $\alpha_{i}$ represents the influence coefficient of the a-type travel mode relative to the other mode; $\alpha_{k}$ represents the influence coefficient of the b-type travel mode relative to the other mode; $K$ represents the total category of travel modes, that is $K=3$. It should be noted that the travel mode here is not equal to its traditional definition, but rather to the passengers' travel choices that we care about.

The cumulative odds model divides the response variables into ordered $k$ levels and calculates the probability of different ones. This model is often

Table 1 -Correlation analysis between influencing factors and changes of travel choices

\begin{tabular}{||c|c|c|c|c||}
\hline Variable I & Variable II & Coefficient & Significance level & Correlation degree \\
\hline \hline Gender & Change travel choices & 0.134 & 0.126 & Insignificant \\
\hline Age & Change travel choices & 0.114 & $0.021^{*}$ & Significant \\
\hline Education & Change travel choices & 0.015 & 0.301 & Insignificant \\
\hline Trip frequency & Change travel choices & 0.087 & $0.046^{*}$ & Significant \\
\hline Approach of achieving RTI & Change travel choices & -0.058 & 0.381 & Insignificant \\
\hline Tolerable waiting time & Change travel choices & -0.206 & $0.012^{*}$ & Significant \\
\hline Travel considerations & Change travel choices & -0.042 & $0.038^{*}$ & Significant \\
\hline RTI distribution & Change travel choices & 0.039 & $0.049^{*}$ & Significant \\
\hline Accuracy of RTI & Change travel choices & 0.24 & $0.037^{*}$ & Significant \\
\hline Frequency of using RTI & Change travel choices & 0.15 & $0.015^{*}$ & Significant \\
\hline
\end{tabular}

Note: * represents $0.01<P<0.05$ 
Table 2 - Numerical transformation and definitions of independent variables

\begin{tabular}{|c|c|c|}
\hline Variable name & Definition & Assignment \\
\hline Gender & $x_{1}$ & Man $=0$ Woman $=1$ \\
\hline \multirow{3}{*}{ Age } & \multirow{3}{*}{$x_{2}$} & $18-30$ years old $=1$ \\
\hline & & $31-45$ years old $=2$ \\
\hline & & Older than 45 year-old $=3$ \\
\hline \multirow{3}{*}{ Education } & \multirow{3}{*}{$x_{3}$} & $\begin{array}{l}\text { Senior high school or technical } \\
\text { secondary school } \\
\text { or lower education=1 }\end{array}$ \\
\hline & & $\begin{array}{l}\text { Bachelor junior college stu- } \\
\text { dent }=2\end{array}$ \\
\hline & & Master or higher degree $=3$ \\
\hline \multirow{3}{*}{$\begin{array}{l}\text { Trip frequen- } \\
\text { cy }\end{array}$} & \multirow{3}{*}{$x_{3}$} & Less than 2 days $=1$ \\
\hline & & $3-5$ days $=2$ \\
\hline & & $6-7$ days $=3$ \\
\hline \multirow{3}{*}{$\begin{array}{l}\text { Frequency of } \\
\text { using RTI }\end{array}$} & \multirow{3}{*}{$x_{4}$} & Usually=1 \\
\hline & & Occasionally $=2$ \\
\hline & & Never $=3$ \\
\hline \multirow{3}{*}{$\begin{array}{c}\text { Tolerable } \\
\text { waiting time }\end{array}$} & \multirow{3}{*}{$x_{5}$} & $5-10$ minutes $=1$ \\
\hline & & $10-15$ minutes $=2$ \\
\hline & & Longer than 15 minutes $=3$ \\
\hline \multirow{3}{*}{$\begin{array}{c}\text { Accuracy of } \\
\text { RTI }\end{array}$} & \multirow{3}{*}{$x_{6}$} & $\begin{array}{l}\text { Very accurate or fairly accu- } \\
\text { rate }=1\end{array}$ \\
\hline & & $\begin{array}{l}\text { Generally accurate or not very } \\
\text { accurate }=2\end{array}$ \\
\hline & & Very inaccurate $=3$ \\
\hline \multirow{5}{*}{$\begin{array}{l}\text { Travel con- } \\
\text { siderations }\end{array}$} & \multirow{5}{*}{$x_{6}$} & Transfer $=1$ \\
\hline & & Detour $=2$ \\
\hline & & Empty seat=3 \\
\hline & & Waiting time $=4$ \\
\hline & & Tickets price $=5$ \\
\hline \multirow{4}{*}{$\begin{array}{l}\text { Displayed } \\
\text { types of infor- } \\
\text { mation }\end{array}$} & \multirow{4}{*}{$x_{7}$} & Time prediction=1 \\
\hline & & Images with character $=2$ \\
\hline & & Images $=3$ \\
\hline & & Character $=4$ \\
\hline \multirow{3}{*}{$\begin{array}{l}\text { Source of } \\
\text { information }\end{array}$} & \multirow{3}{*}{$x_{8}$} & Bus electronic stop $=1$ \\
\hline & & $\begin{array}{l}\text { Applications on smart } \\
\text { phones }=2\end{array}$ \\
\hline & & Newspaper or television $=3$ \\
\hline
\end{tabular}

used in the study of ordinal logistic regression, and is also applicable to the solution of travel choice problem in this paper.

Let the response variable $y$ be an ordered variable with $k$ levels; the independent variable is $X=x_{1}, x_{2}, \ldots, x_{m}$; the probability of ranking $j(j=1,2$, $\ldots, k)$ is $P(y=j \mid x)$; then the probability that the level is less than $j(j=1,2, \ldots, k)$ is as follows:
$P(y \leq j \mid x)=P(y=1 \mid x)+P(y=2 \mid x)+\ldots+P(y=j \mid x)$

Logit transformation of the above formula can be obtained as follows:

$\operatorname{Logit}[P(y \leq j)]=\ln \frac{P(y \leq j \mid x)}{1-P(y \leq j \mid x)}=-\beta_{0}-\sum_{i=1}^{m} \beta_{i} x_{i}$

where $\beta_{0}$ is a constant term; $p$ is between $[0,1] ; \beta_{i}$ is a regression coefficient, which represents the logarithm of the probability that the dependent variable increases by one or more levels for each additional unit of $x_{i}$.

\section{MODELLING RESULTS}

According to the screening principles of the questionnaire, the parameters were computed by SPSS software. By gradually eliminating the variables with significant level lower than $95 \%$, the iterative results of logistic regression analysis under the conditions of going to work/school are shown in Table 3.

\section{Going to work/school}

After 6 iterations, it can be seen from Table 3 that the variables that remained are as follows: frequency of using RTI, tolerable waiting time, accuracy and timeliness of information, and travel considerations when changing routes. These are four variables required for modelling when RTI is available. Modelling results are shown in Formula 6-8.

$$
\begin{aligned}
& \operatorname{Logit}(P \mid \text { Change path often })=-7.275+0.897 x_{5}(1) \\
& +1.305 x_{6}(1)+1.223 x_{7}(1)+0.965 x_{7}(2) \\
& -1.489 x_{8}(1)-1.034 x_{8}(2)-1.129 x_{8}(4)
\end{aligned}
$$

$\operatorname{Logit}(P \mid$ Change path occasionally $)=-5.670$

$$
+0.897 x_{5}(1)+1.305 x_{6}(1)+1.223 x_{7}(1)+0.965 x_{7}(2)
$$$$
-1.489 x_{8}(1)-1.034 x_{8}(2)-1.129 x_{8}(4)
$$

Logit $(P \mid$ Never change path $)=-6.092$

$$
\begin{aligned}
& +0.897 x_{5}(1)+1.305 x_{6}(1)+1.223 x_{7}(1)+0.965 x_{7}(2) \\
& -1.489 x_{8}(1)-1.034 x_{8}(2)-1.129 x_{8}(4)
\end{aligned}
$$

\section{Getting off work or after school}

By gradually eliminating the variables with a significant level lower than $95 \%$, the final logistic regression model under the case of getting off work can be expressed as Formula 9-11.

$$
\begin{aligned}
& \text { Logit }(P \mid \text { Change path often })=-3.245+0.587 x_{5}(1) \\
& +1.193 x_{6}(1)+2.170 x_{7}(1)+1.856 x_{7}(2)-0.765 x_{8}(1) \\
& +0.341 x_{8}(2)+0.229 x_{8}(4)
\end{aligned}
$$


$\underline{\text { Deng Y, Chen M. Impacts of Real-Time Transit Information on Bus Passengers' Travel Choices Based on Travel Behaviour Survey }}$

Table 3 - Iterative results of going to work/school logistic model

\begin{tabular}{|c|c|c|c|c|c|}
\hline & $\mathrm{B}$ & S.E & Wald & Sig. & $\operatorname{EXP}(B)$ \\
\hline Change(1) & -7.275 & 1.330 & 29.615 & 0.000 & - \\
\hline Change(2) & -5.670 & 1.313 & 8.527 & 0.000 & - \\
\hline Change(3) & -6.092 & 1.3225 & 11.796 & 0.000 & - \\
\hline Frequency(1) & 0.897 & 0.412 & 5.766 & 0.027 & 2.714 \\
\hline Frequency $(2)$ & 0.048 & 0.435 & 1.354 & 0.239 & 1.436 \\
\hline Frequency(3) & 0 & - & - & - & - \\
\hline Waiting(1) & 1.350 & 0.799 & 3.891 & 0.039 & 4.203 \\
\hline Waiting(2) & 0.766 & 0.843 & 0.790 & 0.268 & 0.391 \\
\hline Waiting(3) & 0 & - & - & - & - \\
\hline Accuracy(1) & 1.223 & 0.349 & 8.535 & 0.014 & 3.550 \\
\hline $\operatorname{Accuracy}(2)$ & 0.965 & 0.302 & 4.250 & 0.041 & 2.335 \\
\hline Accuracy(3) & 0 & - & - & - & - \\
\hline Travel considerations $(1)$ & -1.489 & 0.532 & 4.645 & 0.021 & 1.210 \\
\hline Travel considerations(2) & -1.034 & 0.601 & 3.992 & 0.043 & 1.008 \\
\hline Travel considerations( 3 ) & 0.765 & 1.212 & 2.355 & 0.102 & 0.342 \\
\hline Travel considerations $(4)$ & -1.129 & 0.438 & 4.027 & 0.004 & 1.535 \\
\hline Travel considerations $(5)$ & 0 & - & - & - & - \\
\hline
\end{tabular}

Logit $(P \mid$ Change path occasionally $)=-1.780$

$+0.587 x_{5}(1)+1.193 x_{6}(1)+2.170 x_{7}(1)+1.856 x_{7}(2)$

$-0.765 x_{8}(1)+0.341 x_{8}(2)+0.229 x_{8}(4)$

$\operatorname{Logit}(P \mid$ Never change path $)=-0.974+0.587 x_{5}(1)$

$+1.193 x_{6}(1)+2.170 x_{7}(1)+1.856 x_{7}(2)-0.765 x_{8}(1)$

$+0.341 x_{8}(2)+0.229 x_{8}(4)$

Combing these two models above, we analysed several independent variables still retained. The meaning of independent variables is shown in Table 4.

Table 4 - Interpretation of independent variables

\begin{tabular}{|c|l||}
\hline $\begin{array}{c}\text { Independent } \\
\text { variable }\end{array}$ & \multicolumn{1}{|c|}{ Interpretation } \\
\hline \hline$x_{2}(1)$ & Age 18-30 \\
\hline$x_{5}(1)$ & Querying information often \\
\hline$x_{6}(1)$ & Tolerable waiting time less than 5 minutes \\
\hline$x_{7}(1)$ & Very accurate and timely information \\
\hline$x_{7}(2)$ & Not very accurate and timely information \\
\hline$x_{8}(1)$ & Transfer \\
\hline$x_{8}(2)$ & Detour \\
\hline$x_{8}(3)$ & Empty seats/comfort level \\
\hline$x_{8}(4)$ & Waiting time \\
\hline$x_{9}(1)$ & Displayed in predicted time \\
\hline$x_{9}(2)$ & Character and images \\
\hline
\end{tabular}

Since the models of going to work and getting off work have been iterated for 6 and 5 times respectively, we got the fitting results shown in Table 5 .

Table 5 reveals the model's goodness of fit under commuting. Firstly, when travellers are going to work or school, the value of -2 Log likelihood is 215.890 in the last iteration. The value of Nagelkerke $R^{2}$ is 0.654 , which is close to 1 , indicating that this model fits well. Each variable is taken into the work model to calculate, and the probability that the passengers will change their path choice is $67.2 \%$. Secondly, in the getting-off-work or after-school model, the value of -2 Log likelihood is 225.105 in the last iteration, and its Nagelkerke $\mathrm{R}^{2}$ is 0.910 , which is higher than that of the work model. Values of these variables are brought into the work model to calculate, and the probability that the passenger will change their line selection is $74.6 \%$. Therefore, the model based on getting-off-work conditions fits better than the other one.

Table 5 - Summary of the model's goodness of fit

\begin{tabular}{|c|c|c|c||}
\hline \hline Step & $\begin{array}{c}-2 \text { Log } \\
\text { likelihood }\end{array}$ & Cox\&Snell $\mathrm{R}^{2}$ & Nagelkerke $\mathrm{R}^{2}$ \\
\hline \hline 1 & 202.989 & 0.507 & 0.542 \\
\hline 6 & 215.890 & 0.554 & 0.654 \\
\hline 1 & 219.489 & 0.654 & 0.774 \\
\hline 5 & 225.105 & 0.662 & 0.910 \\
\hline
\end{tabular}




\section{DISCUSSION}

\subsection{Validation of model}

This section focuses on the feasibility and practicality of the model. Regression analysis is performed based on the degree of change in passengers' travel choice, and the ratio of relative risk (RRR) and constant (Constant) are listed in Table 6. For the analysis of the variance of the influence variable, see Table 6 . The actual sample size of this analysis is $n=660$. The experiment proves that the reliability of the analysis result can be improved by expanding the sample size by 3 times. The goodness ratio coefficients of the two models are 0.6380 and 0.5442 , respectively, which satisfies the minimum threshold of 0.2 for model accuracy, so it is reasonable to assume that the accuracy of the model is high. From the specific numerical point of view, the forecasting accuracy of going-towork model is higher than that of the getting-offwork model. The hit rate of the former is $75.49 \%$, and the hit rate of the latter is $71.99 \%$.
The fitting results are shown in the above table. In the getting-off-work model, it can be seen from the constant term that when other factors remain unchanged, the order of attractiveness of the three kinds of travel choices from high to low is change path choice often, change path choice occasionally, and never change path choice. It can be learned from the specific value that the constant term of change path choice often relative to change path choice occasionally is -0.17 , and the value corresponding to the never change path choice is -6.85 . When other influencing factors remain unchanged, the probability of occurrence of the change path choice often is 0.17 times greater than that of change path choice occasionally, and the probability of change path choice occasionally is 6.68 times greater than never change path choice. The effects of various variables vary from going-to-work model and getting-off-work model. Here are the values of statistic $F$ and $\eta^{2}$ of each variable. Among them, $\eta^{2}$ is the effect coefficient, representing the ratio of the sum of

Table 6 - Comparison of model analysis results

\begin{tabular}{|c|c|c|c|c|c|c|c|}
\hline \multirow{2}{*}{ Travel choice } & \multirow{2}{*}{ Variables } & \multicolumn{3}{|c|}{ Going to work } & \multicolumn{3}{|c|}{ Getting off work } \\
\hline & & Coefficient & Z & RRR & Coefficient & $\mathrm{Z}$ & RRR \\
\hline \multirow{6}{*}{$\begin{array}{c}\text { Change path } \\
\text { often }\end{array}$} & $x_{2}$ & - & - & - & -0.03 & 0.85 & 3.01 \\
\hline & $x_{5}$ & 0.023 & 1.48 & 1.94 & - & - & - \\
\hline & $x_{6}$ & -0.24 & -10.11 & 1.88 & -0.781 & 4.22 & 0.73 \\
\hline & $x_{7}$ & -1.96 & 0.62 & 0.96 & 0.032 & 7.25 & 1.38 \\
\hline & $x_{8}$ & 0.042 & 7.84 & 1.22 & 0.05 & 2.76 & 0.01 \\
\hline & $x_{9}$ & - & - & - & -0.88 & 5.69 & 8.01 \\
\hline \multirow{6}{*}{$\begin{array}{l}\text { Change path } \\
\text { occasionally }\end{array}$} & $x_{2}$ & - & - & - & -0.25 & 1.11 & 2.96 \\
\hline & $x_{5}$ & 0.21 & -0.56 & 2.03 & - & - & - \\
\hline & $x_{6}$ & -2.66 & -3.17 & 0.06 & 0.025 & 0.46 & 1.24 \\
\hline & $x_{7}$ & 0.09 & 1.8 & 0.43 & -0.45 & 1.86 & 0.53 \\
\hline & $x_{8}$ & -2.22 & 0.34 & 1.04 & -4.21 & -10.67 & 0.89 \\
\hline & $x_{9}$ & - & - & - & 0.03 & 0.39 & 1.05 \\
\hline \multirow{6}{*}{$\begin{array}{c}\text { Never change } \\
\text { path }\end{array}$} & $x_{2}$ & - & - & - & -0.05 & 1.15 & 1.73 \\
\hline & $x_{5}$ & -0.15 & 4.22 & 1.81 & - & - & - \\
\hline & $x_{6}$ & -0.33 & 3.91 & 2.05 & -0.88 & 1.23 & 0.81 \\
\hline & $x_{7}$ & -2.5 & 0.15 & 2.12 & 0.03 & 1.27 & 5.14 \\
\hline & $x_{8}$ & 0.27 & 1.32 & 2.08 & 0.015 & 5.1 & 0.36 \\
\hline & $x_{9}$ & - & - & - & 0.07 & 15.1 & 0.009 \\
\hline \multicolumn{2}{|l|}{ Samples size } & \multicolumn{3}{|c|}{1980} & \multicolumn{3}{|c|}{1980} \\
\hline \multicolumn{2}{|c|}{ Likelihood estimation } & \multicolumn{3}{|c|}{-982.14} & \multicolumn{3}{|c|}{-763.25} \\
\hline \multicolumn{2}{|l|}{ Likelihood ratio } & \multicolumn{3}{|c|}{1881.24} & \multicolumn{3}{|c|}{1592.98} \\
\hline \multicolumn{2}{|l|}{ Goodness ratio } & \multicolumn{3}{|c|}{0.638} & \multicolumn{3}{|c|}{0.5442} \\
\hline \multicolumn{2}{|l|}{ Hit rate } & \multicolumn{3}{|c|}{$75.49 \%$} & \multicolumn{3}{|c|}{$71.99 \%$} \\
\hline
\end{tabular}


squares between the groups in the total square sum, and the larger the ratio, the greater the degree of influence.

As shown in Table 7, all kinds of variables have significant differences for the relevant travel modes. But the effect coefficient $\eta^{2}$ is relatively small except for the tolerable waiting time and accuracy of information, which have a slightly higher effect value. The results are basically consistent with the results in Table 6. According to that, the model used is suitable for this study.

Table 7 - Analysis of the variables'variance

\begin{tabular}{||c|c|c|c||}
\hline Variable & $\mathrm{F}$ & $\mathrm{MS}$ & $\eta^{2}$ \\
\hline \hline$x_{2}$ & 4.21 & 2.1 & 0.01 \\
\hline$x_{5}$ & 7.98 & 5.16 & 0.02 \\
\hline$x_{6}$ & 12.69 & 8.18 & 0.01 \\
\hline$x_{7}$ & 8.42 & 12.14 & 0.03 \\
\hline$x_{8}$ & 19.02 & 2.01 & 0.004 \\
\hline$x_{9}$ & 8.32 & 5.13 & 0.02 \\
\hline
\end{tabular}

\subsection{Influencing factors}

Here are several factors that influence passenger satisfaction in a certain trip. According to the results of the survey in section 2 and model estimation, the specific impacts of each main factor on the passenger travel choice are analysed under two different situations: going to work/school and getting off work/school. Among them, there are three common influencing factors of these two types of models. The first is travel considerations when they are changing routes, then there is the accuracy of the information, and the last one is tolerable waiting time of the passengers. In addition, the going-to-work/ school model considers the using frequency of RTI. The getting-off work/out-of school model focuses on passenger age and the displayed form of information. The influencing factors of six models were analysed as shown in Figure 2.

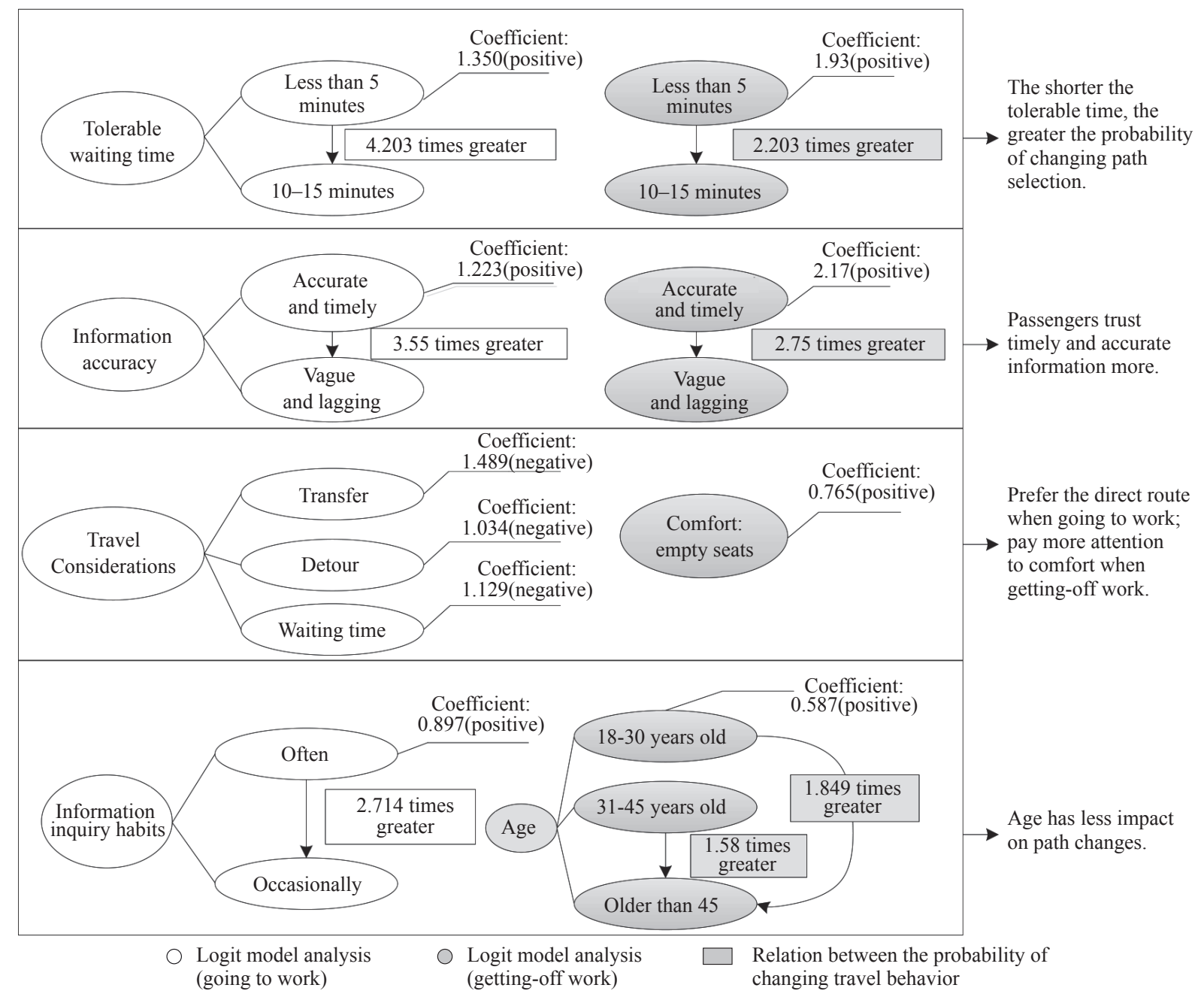

Figure 2 - Analysis of influencing factors in ordinal logistic regression model 
With regression analysis, we know about the probability of the passenger's trust of RTI under two travelling scenarios. That is, the probability of changing the travel choices with RTI is $67.2 \%$ for people who go to work and $74.6 \%$ for those going home, respectively. When passengers are on their way to work/school, they are more willing to use RTI to change their original travel options. This finding is consistent with the results when there are no time constraints [27].

\subsection{Analysis of travel choice change}

In the previous section, it could be seen that travel influencing factors ultimately affect passenger behaviour changes. This study will evaluate four indicators of passenger change in behaviour: travel mode, departure time, routes, and stop choices. In order to specifically examine the changes in these four behaviours, this study calculates the score difference of each surveyed individual with RTI and without it. Taking the travel mode as an example, the experimental group has the RTI service during travels, while the control group does not. The scores and standard deviations of the two groups of data are calculated separately. The results show that the score difference is not significant for the weekly bus travel mode selection $(t=0.54, p=0.631)$, and there is no significant change for the weekly departure time choices $(t=0.46, p=0.593)$. The specific calculation results are shown in Table 8.

Comparing the control group and the experimental group, the average scores of three variables without RTI is lower than variables with RTI. Among them, the average number of changes in the route selection of the control group is 2.17 , and the average number of respondents in the experimental group was 0.98 , which is a significant difference $(t=3.01$, $p=0.0085<0.01$ ). Meanwhile, this paper confirms that RTI can actually reduce the average waiting time of passengers. The average waiting time of the control group in the survey is 6.69 minutes, which is significantly different from the 5.35 minutes of the experimental group $(t=3.01, p=0.0085<0.01)$. This conclusion confirms the efficiency of public transport has been improved. Unlike the analysis of route choices, it is the complexity of stops selection that reflects the influence of RTI in choosing travel stations. The selection of passengers under RTI is more complex, indicating that these respondents display greater uncertainty in the choice of boarding, transfer, and drop-off sites. Taking the passenger's getting-off site as an example, passengers query RTI before setting out and find the planned route near the departure point or if they are experiencing traffic congestion. This congestion will last for some time. At this point, the passengers will combine their own preference for walking distance, decide whether to get off early to walk to the end point. As a result, the passengers' site selection complexity has increased.

Based on the conclusion and experience of some previous studies, there may be cases where the passengers' perceived time is inconsistent with the actual waiting time [27]. In the survey's results, $74.8 \%$ of passengers usually checked the information before leaving home or workplace; and 19.9\% of passengers occasionally checked the information; only $5.3 \%$ of passengers said they never checked RTI. Therefore, the frequency of checking information can be used to explore the impact of RTI on passenger perceived waiting time, and further explore their changes of travel choice. However, after analysing the questionnaire and other related studies, we found this information lacking in diversity and displaying insufficient flexibility. Moreover, the form of the information also needs to be further improved. According to the survey, $87.2 \%$ of passengers prefer information in the time prediction category, and the preference for text-based information is $67.7 \%$. In view of several popular bus information applications, it is still necessary to provide more accurate forecasting time, such as bus arrival time, transfer

Table 8 - Statistical results of four changes in travel choice

\begin{tabular}{||l|c|c|c|c|c|c||}
\hline \multirow{2}{*}{ Behaviour changes } & \multicolumn{2}{|c|}{ Control group } & \multicolumn{2}{c|}{ Experimental group } & \multicolumn{2}{c||}{ Difference } \\
\cline { 2 - 8 } & Sample size & $\begin{array}{c}\text { Mean } \\
\text { (standard } \\
\text { deviation) }\end{array}$ & Sample size & $\begin{array}{c}\text { Mean } \\
\text { (standard } \\
\text { deviation) }\end{array}$ & T-stat & P-value \\
\hline \hline Change travel mode & 80 & $6.839(3.94)$ & 80 & $6.75(3.83)$ & 0.54 & 0.631 \\
\hline Adjust departure time & 90 & $4.44(4.03)$ & 90 & $4.07(3.63)$ & 0.46 & 0.593 \\
\hline Bus route and vehicle choice & 75 & $10.61(4.07)$ & 75 & $10.46(4.37)$ & 3.01 & 0.0085 \\
\hline Stop choice & 85 & $23.94(3.26)$ & 85 & $16.25(1.02)$ & 1.73 & 0.00094 \\
\hline
\end{tabular}


time, etc., which will greatly help to reduce passenger anxiety $[16,28]$. As the following aspects, we can foresee the improvement of the efficiency of the public transport system:

1) Bus passengers who travelled only based on experience in the past can now use the multi-line and multi-scheme selection provided by RTI to proactively avoid the congested path, which is conducive to the dispersion of passenger flow on the bus line during peak hours.

2) Under the influence of the RTI service, the time spent by some passengers on the bus has decreased. On the one hand, it may be because they arrived at the destination as soon as possible; on the other hand, they may have chosen walking or other means with reference to RTI, thereby shortening the total travel time. The realisation of these advantages and benefits must rely on the efficient and advanced RTI service system.

\section{CONCLUSION AND FUTURE RESEARCH}

In this paper, we used survey data of 660 bus passenger travel behaviours from Xi'an, China to assess the impact of RTI on the passengers' change of their travel choice. The survey data included personal attributes of the passengers, travelling attributes, preference on changing path, and attitudes towards RTI. Based on the data analysis, we designed a statistical experiment that integrated the survey data to facilitate the review of decision-making changes before and after the use of RTI.

Based on the ordinal logistic regression model, we found that with different time constraints, RTI affects passenger path choice differently. However, the analysis of the questionnaire and the ordinal logistic regression model showed that tolerable waiting time, accuracy of information, and travel considerations when changing path choice had significant impacts on passenger selections, whether there were time constraints or not. For the trips of going to work or school, passengers were more sensitive to tolerable waiting time and accuracy of the RTI service than when they were getting off work, as they were often faced with time constraints when going to work. If there was inaccurate information, they would not easily change the original travel plan. Otherwise, they would be late for work or school and suffer financial losses.
Therefore, the passengers' trust in RTI depended, to a large extent, on the accuracy and timelines of the information, especially for the commuters. This study also found that the higher the accuracy of RTI was, the higher the frequency became, with which passengers change the line selection based on the information provided.

After analysing passenger behavioural changes, this study confirmed the impact of RTI on the passenger decision-making process, and obtained the probability of occurrence of different travel choices. Passengers adjusted their travel arrangements because of this information, and once they believe that such changes would have beneficial impacts, these diverse choices will greatly help improve the utilisation of the public transport system. Also, analysing passengers' travel choices in the public transport network helped to make the planning of network more reasonable.

This study still has some limitations that are worth noting. The results obtained in this questionnaire were based on the samples of 660 public transport passengers in Xi'an, China. However, the multivariate analysis captured significant relations that could be investigated in the future on a larger scale. In terms of using the ordinal logistic regression model to predict the passenger's travel choice, there might be broader applications if the sample size and investigating area can be further expanded. Secondly, the results of the questionnaire were derived from the information that the passengers filled out and reported subjectively, which means there may be some biases or deviation between the survey results and the actual situation.

This research will help us to have a clearer understanding of the route choice behaviour of bus travellers. Further research can verify the quantified benefits that RTI brings to the passengers, such as how to reduce their waiting time, ease their anxiety, and improve their satisfaction.

\section{ACKNOWLEDGEMENTS}

The research is supported by the National Key Research and Development Program of China (grant No. 2018YFB1600900), the Shaanxi Provincial Science and Technological Project (grant No. 2020JM-244), the Science and Technological Project of Shaanxi Provincial Transport Department (grant No. 19-24X), and in part by the Fundamental Research Funds for the Central Universities (grant No. 300102210204). 


\section{邓亚娟}

Email: yjdeng@chd.edu.cn

长安大学运输工程学院, 陕西 西安, 710064

陈明丽 (通讯作者)

E-mail: 2018221235@chd.edu.cn

长安大学运输工程学院, 陕西 西安, 710064

\section{实时信息对公交乘客出行选择行为的影响}

\section{摘要}

实时公交信息 $(R T I)$ 服务可以为出行者提供与 公交系统有关的各类信息, 出行者可以根据其需 求, 利用这些信息更合理地安排出发时间和出行方 式。本文建立RTI服务下的公交乘客出行选择行为 模型, 解释实时信息相关因素与乘客出行行为改变 之间的关系，为实时公交信息服务系统的改善提供 有效的建议。本研究基于意向性偏好 $(S P)$ 调查数 据, 建立了有序逻辑回归模型, 分析 $R T I$ 下公交乘客 出行行为的变化概率。模型计算结果表明: 下班时 出行者更有可能根据RTI改变他们的行为选择; 比较 对照组和实验组的数据发现, 有RTI服务的乘客比没 有RTI服务的乘客在出行方式、出发时间、车辆和换 乘站的选择上复杂程度更高。本文成果可为智能公 交出行信息系统的优化及 RTI的发布策略提供参考, 同时有助于提升公交网络的规划质量。

\section{关键词}

实时公交信息; 出行决策; 乘客行为变化; 出行时间

\section{REFERENCES}

[1] Brakewood C, Watkins K. A literature review of the passenger benefits of real-time transit information. Transport Reviews. 2019;39(3): 327-356. DOI: 10.1080/01441647.2018.1472147

[2] Brakewood C, Barbeau S, Watkins K. An experiment evaluating the impacts of real-time transit information on bus riders in Tampa, Florida. Transportation Research Part A: Policy and Practice. 2014;69: 409-422. DOI: 10.1016/j.tra.2014.09.003

[3] Carrel A, Halvorsen A, Walker JL. Passengers' perception of and behavioral adaptation to unreliability in public transportation. Transportation Research Record. 2013;2351(1): 153-162. DOI: 10.3141/2351-17

[4] Páez A, Whalen K. Enjoyment of commute: A comparison of different transportation modes. Transportation Research Part A: Policy and Practice. 2010;44(7): 537549. DOI: $10.1016 /$ j.tra.2010.04.003

[5] Brakewood C, Macfarlane GS, Watkins K. The impact of real-time information on bus ridership in New York City. Transportation Research Part C: Emerging Technologies. 2015;53: 59-75. DOI: 10.1016/j.trc.2015.01.021

[6] $\mathrm{Lu} \mathrm{H}$, et al. The impact of real-time information on passengers' value of bus waiting time. Transportation Research Procedia. 2018;31: 18-34. DOI: 10.1016/j.trpro.2018.09.043

[7] Carrel A, Halvorsen A, Walker JL. Passengers' perception of and behavioral adaptation to unreliability in public transportation. Transportation Research Record. 2013;235(1): 153-162. DOI: 10.3141/2351-17

[8] Wong J, Reed L, Watkins K, Hammond R. Open transit data: State of the practice and experiences from participating agencies in the United States. Proceedings of the 2013 Annual Meeting of the Transportation Research Board; 2013.

[9] Fonzone A, Schmöcker JD. Effects of transit real-time information usage strategies. Transportation Research Record. 2014;2417(1): 121-129. DOI: 10.3141/2417-13

[10] Watkins KE, et al. Where is my bus? Impact of mobile real-time information on the perceived and actual wait time of transit riders. Transportation Research Part A: Policy and Practice. 2011;45(8): 839-848. DOI: 10.1016/ j.tra.2011.06.010

[11] Brakewood CE. Quantifying the Impact of Real-Time Information on Transit Ridership. PhD thesis. Georgia Institute of Technology; 2014.

[12] Liu Y, Shi J, Jian M. Understanding visitors' responses to intelligent transportation system in a tourist city with a mixed ranked logit model. Journal of Advanced Transportation. 2017; 1-13. DOI: 10.1155/2017/8652053

[13] Zeng Y, Li J, Zhu H. Pedestrian path selection behavior under real-time information. Journal of Computer Applications. 2013;33(10): 2964-2968. Chinese.

[14] Mulley C, Clifton GT, Balbontin C, Ma L. Information for travelling: Awareness and usage of the various sources of information available to public transport users in NSW. Transportation Research Part A: Policy and Practice. 2017;101(C): 111-132. DOI: 10.1016/j.tra.2017.05.007

[15] Tang L, Thakuriah PV. Ridership effects of real-time bus information system: A case study in the City of Chicago. Transportation Research Part C: Emerging Technologies. 2012;22: 146-161. DOI: 10.1016/j.trc.2012.01.001

[16] $\mathrm{Hu} \mathrm{X}$, et al. Behavioral responses to pre-planned road capacity reduction based on smartphone GPS trajectory data: A functional data analysis approach. Journal of Intelligent Transportation Systems. 2019;23(2): 133-143. DOI: $10.1080 / 15472450.2018 .1488133$

[17] Zhang F, Shen Q, Clifton KJ. Examination of traveler responses to real-time information about bus arrivals using panel data. Transportation Research Record. 2008;2082(1): 107-115.

[18] Gooze A, Watkins KE, Borning A. Benefits of real-time transit information and impacts of data accuracy on rider experience. Transportation Research Record. 2013;2351(1): 95-103.

[19] Tang L, Thakuriah P. Will the psychological effects of real-time transit information systems lead to ridership gain? Transportation Research Record. 2011;2216(1): 67-74.

[20] Drabicki A, Kucharski R, Cats O, Fonzone A. Simulating the effects of real-time crowding information in public transport networks. 2017 5th IEEE International Conference on Models and Technologies for Intelligent Transportation Systems (MT-ITS), Naples; 2017. p. 675-680. DOI: 10.1109/MTITS.2017.8005598

[21] Chen Y, et al. Travel mode prediction model based on Logit of low carbon psychological latent variables. Journal of Highway and Transportation Research and 
Development. 2017;34(09): 100-108+137. Chinese.

[22] Hickman MD, Wilson NHM. Passenger travel time and path choice implications of real-time transit information. Transportation Research Part C: Emerging Technologies. 1995;3(4): 211-226. DOI: 10.1016/0968090X(95)00007-6

[23] Cats O, Loutos G. Evaluating the added-value of online bus arrival prediction schemes. Transportation Research Part A: Policy and Practice. 2016;86: 35-55. DOI: 10.1016/j.tra.2016.02.004

[24] Dziekan K, Kottenhof K. Dynamic at-stop real-time information displays for public transport: Effects on customers. Transportation Research Part A: Policy and Practice. 2007;41(6): 489-501. DOI: 10.1016/ j.tra.2006.11.006

[25] Tang Q, Hu X. Triggering behavior changes with information and incentives: An active traffic and demand management-oriented review. Advances in Transport Policy and Planning. 2019;3: 209-250. DOI: 10.1016/ bs.atpp.2019.05.002

[26] Ben-Elia E, Shiftan Y. Which road do I take? A learning-based model of route-choice behavior with real-time information. Transportation Research Part A: Policy and Practice. 2010;44(4): 249-264. DOI: 10.1016/ j.tra.2010.01.007

[27] Gu Y, Han Y, Fang X. Research on passenger flow forecasting method of public transport hub station based on ARMA model. Journal of Transport Information and Safety. 2011;29(02): 5-9. Chinese.

[28] De Vos J. Do people travel with their preferred travel mode? Analyzing the extent of travel mode dissonance and its effect on travel satisfaction. Transportation Research Part A: Policy and Practice. 2018;117: 261-274. DOI: $10.1016 /$ j.tra.2018.08.034 